\title{
AIDS Dementia Is Associated with Massive, Activated HIV-1 Infection and Concomitant Expression of Several Cytokines
}

\author{
Gerard J. Nuovo and Maria Lynn Alfieri \\ Department of Pathology, State University of New York at Stony \\ Brook, Stony Brook, New York, U.S.A.
}

\begin{abstract}
Background: We recently showed that acquired immunodeficiency syndrome (AIDS) dementia is associated with activated infection of microglia, neurons, and astrocytes by HIV-1. However, it is doubtful whether infection per se is responsible for the dramatic symptoms associated with AIDS dementia. The purpose of this study was to determine the histologic distribution of messenger RNAs (mRNAs) of several cytokines that have been implicated in AIDS pathogenesis and to correlate this expression pattern with the in situ localization of polymerase chain reaction (PCR)-amplified HIV-1 nucleic acids in the central nervous system (CNS).

Materials and Methods: HIV-1 DNA was detected by PCR in situ hybridization. HIV-1 RNA and cytokine expression, including tumor necrosis factor $\alpha$ (TNF), inducible nitric oxide synthetase (iNOS), and macrophage inflammatory protein $\alpha(\mathrm{MIP}-1 \alpha)$ and MIP-1 $\beta$ mRNA were detected by reverse transcriptase (RT) in situ PCR.
\end{abstract}

\begin{abstract}
Results: Amplified viral DNA was detected in each of the seven HIV-1-positive cases and in none of the five negative controls. In people with AIDS dementia, many HIV-1 DNA-positive cells were detected in regions of the CNS that corresponded to clinical symptomatology. In AIDS patients with minimal CNS involvement, rare HIV1-infected microglial cells were noted. Viral RNA was detected primarily in cases of AIDS dementia. TNF, iNOS, MIP- $1 \alpha$ and MIP-1 $\beta$ expression localized to tissues from AIDS dementia cases where HIV-1 infected cells were plentiful. Colocalization experiments showed that these cytokines were transcribed mostly by viral-negative cells. Conclusions: These results suggest that two key elements in AIDS dementia are massive productive viral infection, involving microglia, neurons, and astrocytes, and concomitant stimulation of cytokine transcription in the neighboring uninfected cells.
\end{abstract}

\section{INTRODUCTION}

Clinically obvious central nervous system (CNS)disease is found in many people with acquired immunodeficiency syndrome (AIDS), especially in the later stages of their disease. The most severe form of this disease is AIDS dementia, where the patient typically experiences difficulty with a variety of cognitive and motor functions. Observations from virologic and pathologic studies have suggested that infection of the CNS by human immunodeficiency virus 1 (HIV-l) occurs commonly in the early stages of the disease $(1,2)$. The clinical manifestations of AIDS de-

Address correspondence and reprint requests to: Gerard J. Nuovo, Department of Pathology, SUNY at Stony Brook, Stony Brook, NY 11794-8691, U.S.A. mentia suggests a cerebral-based process. The histologic features, by no means specific, includes neuronal loss, myelin loss, and occasional accumulations of microglial cells and multinucleated macrophage cells $(1,2)$.

In vivo and in vitro studies have suggested that all the cell components of the CNS-neurons, astrocytes, macrophages/microglial cells, and oligodendroglial cells-can be infected by HIV-1 (3-9). In a previous work, we showed using in situ polymerase chain reaction (PCR), in patients with AIDS dementia, that many cells were infected by HIV-1, and these included neurons and astrocytes as well as the microglial cell/ macrophages. The infection was found to be productive, based on the observation that many 
infected cells contained spliced HIV-1 RNA (9). This suggested that direct viral infection of neurons was responsible, in part, for the devastating clinical findings of AIDS dementia. However, it is doubtful that HIV-l infection is the only factor responsible for AIDS dementia.

There are many theories that attempt to explain the CNS damage associated with HIV-1. These include gp120 neuronal toxicity, immunologic-mediated damage due to common epitopes such as gp4l and an astrocyte cell surface antigen, and the production of cytokines, such as tumor necrosis factor (TNF), by microglial cells and/or astrocytes, which hinders neuronal function and can cause oligodendroglial cell death and, thus, demyelinization $(5,10,11)$. Other cytokines that have been implicated in the pathogenesis of AIDS, either by modulating viral expression and/or inducing damage in the involved tissues, include inducible nitric oxide synthetase (iNOS), macrophage inflammatory protein $\alpha$ (MIP- $1 \alpha)$ and MIP-1 $\beta(12,13)$.

A major impediment to the understanding of the role of cytokine expression in AIDS dementia is that viral and host nucleic acids may be difficult to localize directly by standard in situ hybridization, as the copy number may be below the 10-copy per cell detection threshold $(9,14,15)$. Several investigators including ourselves have detected in situ PCR-amplified HIV-1 DNA and CDNA as well as human mRNA that were not evident with standard in situ hybridization $(9,14-16)$. Although determining the histologic distribution of cytokine mRNA would be useful, it is important to determine whether viral infected cells or uninfected cells are primarily responsible for their synthesis. The purpose of this study was to use the reverse transcriptase (RT) in situ PCR amplification technique to determine the histologic distribution of cytokine expression in patients with AIDS dementia relative to HIV-1 and to compare this with findings in people with AIDS who do not have CNS symptomatology. Colocalizing experiments were used to determine whether viral-infected cells or their viral-negative neighbors were responsible for cytokine expression.

\section{MATERIALS AND METHODS}

\section{Patient Selection}

Brain and spinal cord tissue that was fixed in $10 \%$ buffered formalin were studied from seven patients who had died of AIDS. Four of these people had severe CNS symptomatology, including three cases of AIDS dementia, whereas the other three had no specific CNS symptomatology. These cases were chosen in order to compare the histologic distribution of the virus in a wide pathologic and clinical spectrum. Multiple regions of the brain were studied in the patients with AIDS dementia, corresponding to regions of severe (cerebrum) and minimal (cerebellum and midbrain) symptomatology. None of the cases was used in our prior study of AIDS dementia (9) except for Case 1; in this study, different tissue samples were analyzed. Tissues from the CNS of five patients who had died from a variety of causes and who had no risk factors or evidence of AIDS were studied as negative controls.

\section{In Situ Hybridization}

The probes used for HIV-1 detection were SK19 and SK102 (Perkin-Elmer Corp., Norwalk, CT, U.S.A.) and were labeled with digoxigenindUTP. These correspond the gag region. The standard in situ hybridization protocol used for these oligoprobes has been previously published $(9,14,15)$. Briefly, after protease digestion (2 $\mathrm{mg} / \mathrm{ml}$ of trypsin at $37^{\circ} \mathrm{C}$ for $10-15 \mathrm{~min}$ ) the probe $(50 \mathrm{ng} / \mathrm{ml}$ in a solution of $10 \%$ formamide, $5 \%$ dextran sulfate, and $300 \mathrm{mM} \mathrm{NaCl}$ ) and target DNA are simultaneously denatured by heating to $100^{\circ} \mathrm{C}$ for $5 \mathrm{~min}$. The chromogen NBT/ BCIP (Digene Diagnostics, Gaithersburg, MD, U.S.A.) produces a dark blue hybridization signal, whereas the counterstain nuclear fast red stains nuclei and cytoplasm pink.

\section{PCR in Situ Hybridization and RT in Situ PCR}

Our procedure for detection of PCR-amplified HIV-1 DNA has been published previously $(9,14,15)$. The primers SK38 and SK39 plus SK145 and SK431 (nucleotides 1369-1395 to 1507-1481) are used with the probes SK19 and SK102, respectively. Procedural modifications for RT in situ PCR include the following: after protease digestion which ranged from 60 to 120 min, the tissue was incubated overnight in a RNase-free DNase solution (Boehringer Mannheim, 10 units/section) at $37^{\circ} \mathrm{C}$, which eliminates nonspecific DNA repair and mis-priming; the DNase digestion permits direct incorporation of digoxigenin dUTP $(10 \mu \mathrm{M})$ into the PCR product. The RT and PCR steps were performed in 
TABLE 1. Detection of HIV-1 DNA and RNA, and cellular RNA by in situ PCR in AIDS patients with no CNS symptomatology

\begin{tabular}{llccccc}
\hline & $\begin{array}{c}\text { HIV-1 } \\
\text { DNA }\end{array}$ & $\begin{array}{c}\text { HIV-1 } \\
\text { RNA }\end{array}$ & $\begin{array}{c}\text { iNOS } \\
\text { RNA }\end{array}$ & $\begin{array}{c}\text { TNF } \\
\text { RNA }\end{array}$ & $\begin{array}{c}\text { MIP-1 } \alpha \\
\text { RNA }\end{array}$ & $\begin{array}{c}\text { MIP-1 } \beta \\
\text { RNA }\end{array}$ \\
\hline $\begin{array}{l}\text { Case 1 } \\
\quad \text { Cerebrum }\end{array}$ & $1+^{a}$ & 0 & 0 & 0 & 0 & 0 \\
$\begin{array}{l}\text { Case 2 } \\
\quad \text { Cerebrum }\end{array}$ & $1+$ & 0 & 0 & 0 & 0 & 0 \\
$\quad \begin{array}{l}\text { Cerebellum } \\
\text { Case 3 }\end{array}$ & 0 & $\mathrm{ND}^{b}$ & ND & ND & 0 & 0 \\
$\quad \begin{array}{l}\text { Midbrain } \\
\text { Cerebrum }\end{array}$ & 0 & 0 & 0 & ND & ND & ND \\
\hline
\end{tabular}

${ }^{a}$ The number of positive cells was determined by analyzing serial sections. If between 1 and 10 positive cells were identified in a $200 \times$ field, the case was scored as $1+$, between 11 and 25 positive cells, $2+$, and greater than 25 positive cells, $3+$.

${ }^{b} \mathrm{ND}$, not done.

one reaction mixture by the use of $\mathrm{rTth}$, as previously described (17). Viral RNA detection was performed with the gag-specific primers listed above. Primers for TNF detection were previously reported (9). The primers for iNOS, MIP$1 \alpha$, and MIP- $1 \beta$ mRNA detection were generously provided by Drs. Michael Bukrinsky and Barbara Sherry $(12,13)$.

For colocalization of viral and host RNAs, two separate RT in situ PCR reactions were performed on the same tissue section. For viral RNA, the reporter nucleotide was digoxigenin and for the human mRNA it was ${ }^{3} \mathrm{H}$ dCTP, used at a ratio of 5:1 with unlabeled dCTP, as previously reported (14).

\section{RESULTS}

Fifteen tissues from the CNS of seven patients with AIDS and five tissues from five patients without evidence of HIV-1 infection taken from the cerebrum, cerebellum, and brain stem were studied. Of the seven patients with AIDS, four had long-standing and severe clinical CNS disease that correlated with widespread CNS histologic changes that included marked neuronal loss evident on routine histologic staining, demyelinization, and the microglial nodules and multinucleated giant cells diagnostic of HIV-1 encephalitis. Two of these patients (age 37 and 52, respectively) had long-standing dementia, one (age 5) had severe retardation of motor and developmental skills and the other (age 5) had a 2-year history of seizure disorder of unknown etiology. Their CD4 counts were all less than 34 at the time of death. Of the other three people with AIDS, each showed either minimal or "nonspecific" histologic CNS changes that corresponded to a lack of clinical evidence of AIDS dementia. Their ages were 5, 38, and 39 years, and each had a CD4 count of less than 30 .

The 20 tissues (including the five controls) were analyzed for sequences homologous to HIV-1 DNA using standard in situ hybridization with and without prior PCR amplification. Serial sections were studied using the probe SK19, and probe SK102, respectively. HIV-1 DNA was detected in only two tissues, each from people with AIDS dementia, and in rare cells when standard in situ hybridization was used. When in situ hybridization was preceded by PCR amplification with the appropriate oligomers (SK38/SK39 and SK145/SK431 for SK19 and SK102, respectively), the detection rate increased to $13 / 15$ in the tissues from patients with AIDS. Analysis of adjacent serial sections demonstrated a similar distribution of the PCR-amplified signal using the SK19 and the SK102 probes with their respective primers (data not shown). The PCR-enhanced hybridization signal was not evident if the tissue was DNased prior to PCR or if the Taq polymerase was omitted. No viral DNA was detected in any of the five controls (data not shown).

There was a marked disparity in the location and number of cells positive for PCR-amplified HIV-1 DNA in the tissues from the seven patients. As evident from Table 1 , in the three 

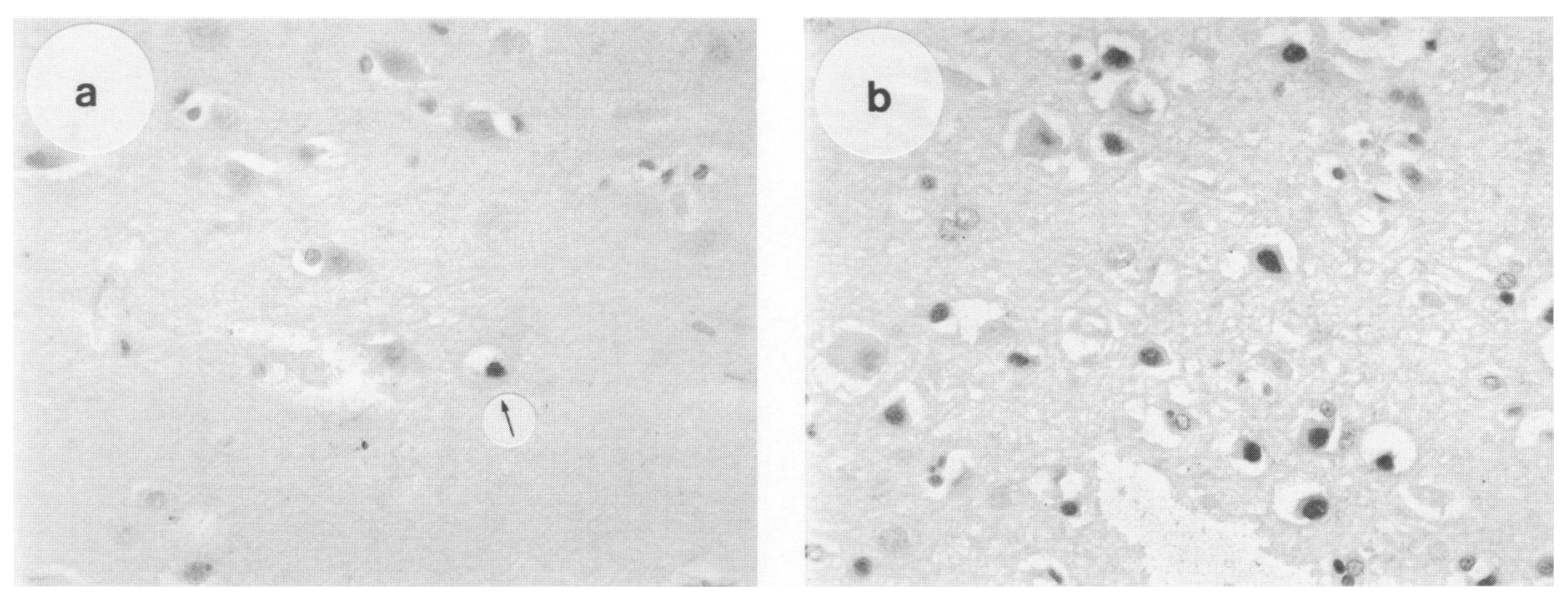

FIG. 1. Correlation of the detection of PCR-amplified HIV-1 DNA in the CNS with the clinical disease state

HIV-1 DNA was detected in rare cells (arrow) after PCR in situ hybridization in this cerebral tissue from a person who had AIDS and minimal CNS symptomatology (a). Many more infected cells were detected by PCR in situ hybridization in the cerebral tissue of a person who had AIDS dementia (b).

people who had minimal CNS disease, rare (less than $1 \%$ of cells in the tissue section) small, round to oval viral-positive cells were identified which localized in and around the perivascular spaces (Fig. 1). In the four people with severe CNS symptomatology, many other positive cells were seen in the tissues from the cerebrum (Table 2). The HIV-1-infected cells were most nu-

TABLE 2. Detection of HIV-1 DNA and RNA, and cellular RNA by in situ PCR in patients with severe CNS symptomatology

\begin{tabular}{|c|c|c|c|c|c|c|}
\hline & $\begin{array}{l}\text { HIV-1 } \\
\text { DNA }\end{array}$ & $\begin{array}{c}\text { HIV-1 } \\
\text { RNA }\end{array}$ & $\begin{array}{l}\text { iNOS } \\
\text { RNA }\end{array}$ & $\begin{array}{r}\text { TNF } \\
\text { RNA }\end{array}$ & $\underset{\text { MNP-1 } \alpha}{\text { RNA }}$ & $\begin{array}{c}\text { MIP-1 } \beta \\
\text { RNA }\end{array}$ \\
\hline \multicolumn{7}{|l|}{ AIDS Dementia } \\
\hline \multicolumn{7}{|l|}{ Case 1} \\
\hline Cerebrum-1 & $3+^{a}$ & $3+$ & $1+$ & $2+$ & 0 & $1+$ \\
\hline Cerebrum-2 & $3+$ & $3+$ & $2+$ & $2+$ & $2+$ & $2+$ \\
\hline Cerebellum & $1+$ & $1+$ & $1+$ & $2+$ & $1+$ & $1+$ \\
\hline Midbrain & $1+$ & 0 & 0 & 0 & $1+$ & 0 \\
\hline \multicolumn{7}{|l|}{ Case 2} \\
\hline Cerebrum-1 & $3+$ & $3+$ & $2+$ & $2+$ & $2+$ & $2+$ \\
\hline Cerebrum-2 & $3+$ & $3+$ & $3+$ & $2+$ & $2+$ & $1+$ \\
\hline Cerebellum & $1+$ & $1+$ & 0 & 0 & 0 & 0 \\
\hline Chiasm & $1+$ & 0 & 0 & 0 & 0 & 0 \\
\hline \multicolumn{7}{|l|}{ Case 3} \\
\hline Cerebrum & $3+$ & $3+$ & $2+$ & $1+$ & $2+$ & 0 \\
\hline \multicolumn{7}{|c|}{ Seizure Disorder } \\
\hline \multicolumn{7}{|l|}{ Case 4} \\
\hline Cerebrum & $2+$ & $2+$ & $2+$ & $2+$ & $1+$ & $2+$ \\
\hline
\end{tabular}

${ }^{a}$ The number of positive cells was determined by analyzing serial sections. If between 1 and 10 positive cells were identified in a $200 \times$ field, the case was scored as $1+$, between 11 and 25 positive cells, $2+$, and greater than 25 positive cells, $3+$. 

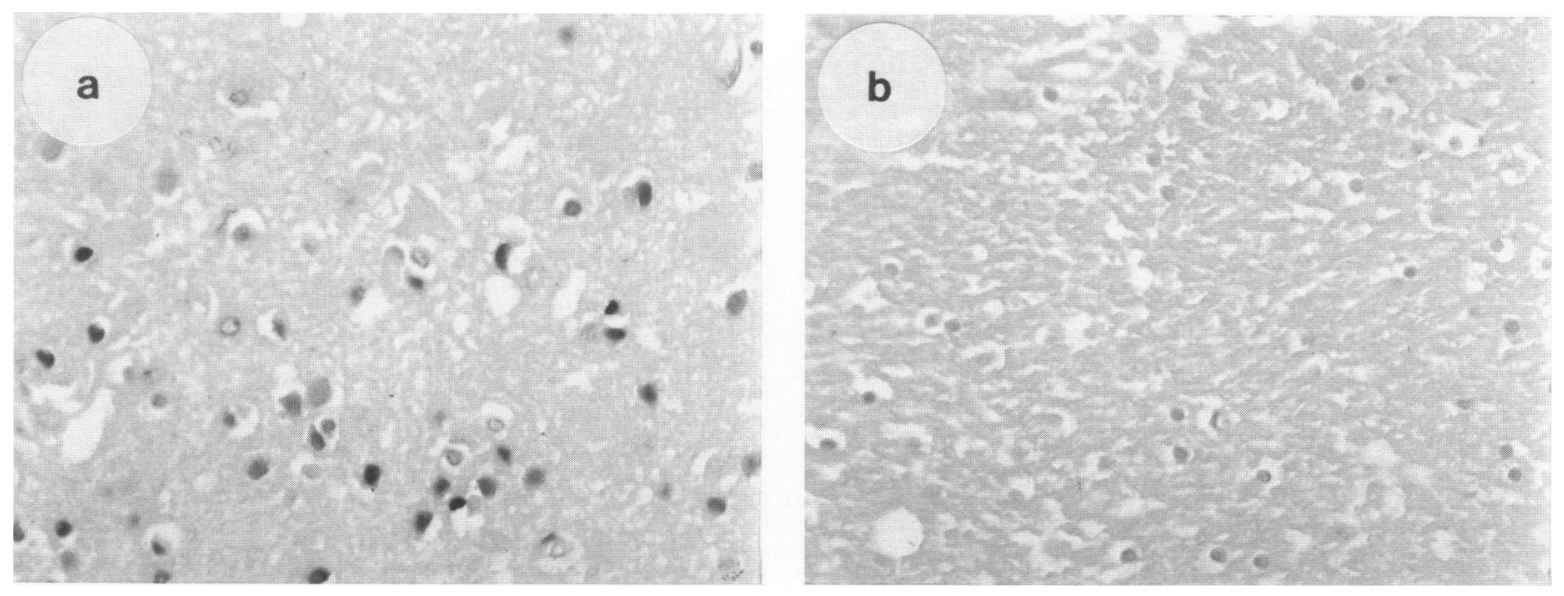

FIG. 2. Correlation of the detection of PCR-amplified HIV-1 RNA and topography in a person with AIDS dementia

HIV-1 RNA was detected in many cells in an equivalent distribution to HIV-1 DNA (see Fig. 1b) in the serial section of the cerebrum using RT in situ PCR (a). However, viral RNA was not detected in the section of the midbrain from this person where HIV-1 DNA positive cells were rarely observed (b).

merous in the area of the gray matter, although viral-positive cells were also evident in the white matter (Fig. 1). Although provirus was most readily identified in the tissues from areas of demyelinization, microglial nodules, and/or neuronal loss, it was also evident in areas of the tissues from the cerebrum where these pathologic features were not evident. The percentage of HIV-1-positive cells from the cerebral tissues of the three patients with AIDS dementia and the one with a seizure disorder ranged from 3 to $11 \%$ of the microglial cells/macrophages, 8 to $15 \%$ of the neurons, and 1 to $3 \%$ of the astrocytes. Determination of cellular phenotype was done by immunohistochemical colabeling, as previously reported (9).

To determine if HIV-l distribution in the people with AIDS dementia correlated with CNS topography, tissues from the cerebellum and midbrain were studied, as the patients showed few symptoms ascribable to these regions. This data, also compiled in Table 2, demonstrated that much fewer HIV-I DNA-positive cells were found in these regions.

To ascertain whether the infection was latent or active with viral transcription, the tissues were analyzed for HIV-1 RNA with RT in situ PCR and the gag-specific primer pairs. The number and distribution of HIV-1 RNA-positive cells from the cerebral sections from the four people with severe CNS symptomatology was equivalent to that of PCR-amplified HIV-1 DNA (Table 2 and Fig. 2). The specificity of the signal with RT in situ PCR was demonstrated by its loss with the omission of the primers, or with the use of irrelevant (human papillomavirus 18) specific primers. The SK38/39 and SK145/431 primer pairs cannot distinguish between genomic HIV-1 RNA and spliced transcripts. A primer pair that either does not amplify or poorly amplifies a target in genomic viral RNA due to its large size of $3500 \mathrm{bp}$ and robustly amplifies a 250 -bp product after splicing in the rev and tat exons (kindly provided by Dr. Roger Pomerantz) produced an intense signal after RT in situ PCR in most of the cells that showed a signal using the other primer pairs (data not shown). Viral RNA was not detected in the three tissues from people with AIDS who did not demonstrate CNS symptomatology (Table 1).

To determine if expression of TNF $\alpha$, iNOS, MIP- $1 \alpha$, and MIP-1 $\beta$ correlated with AIDS dementia, serial (subjacent) sections that were 4 $\mu \mathrm{m}$ distal to the samples used for viral nucleic acid analysis were studied. In the four people with severe CNS symptomatology, cells with TNF, iNOS, MIP- $1 \alpha$, and MIP- $1 \beta$ cDNA were readily identified in those areas where many viral-infected cells were evident (Table 2). Most of the cells expressing these cytokines were microglial cells/macrophages or astrocytes (Fig. 3), although occasional neurons expressed iNOS and MIP- $1 \alpha$ and MIP-1 $\beta$. Expression of these cytokines was less evident from these people with AIDS dementia in the sections of cerebellum and midbrain, where viral-infected cells were less frequent (Table 2). Similarly, cytokine transcription was not evident in the tissues of the AIDS patients who did not have CNS-related symptoms (Table 1). 

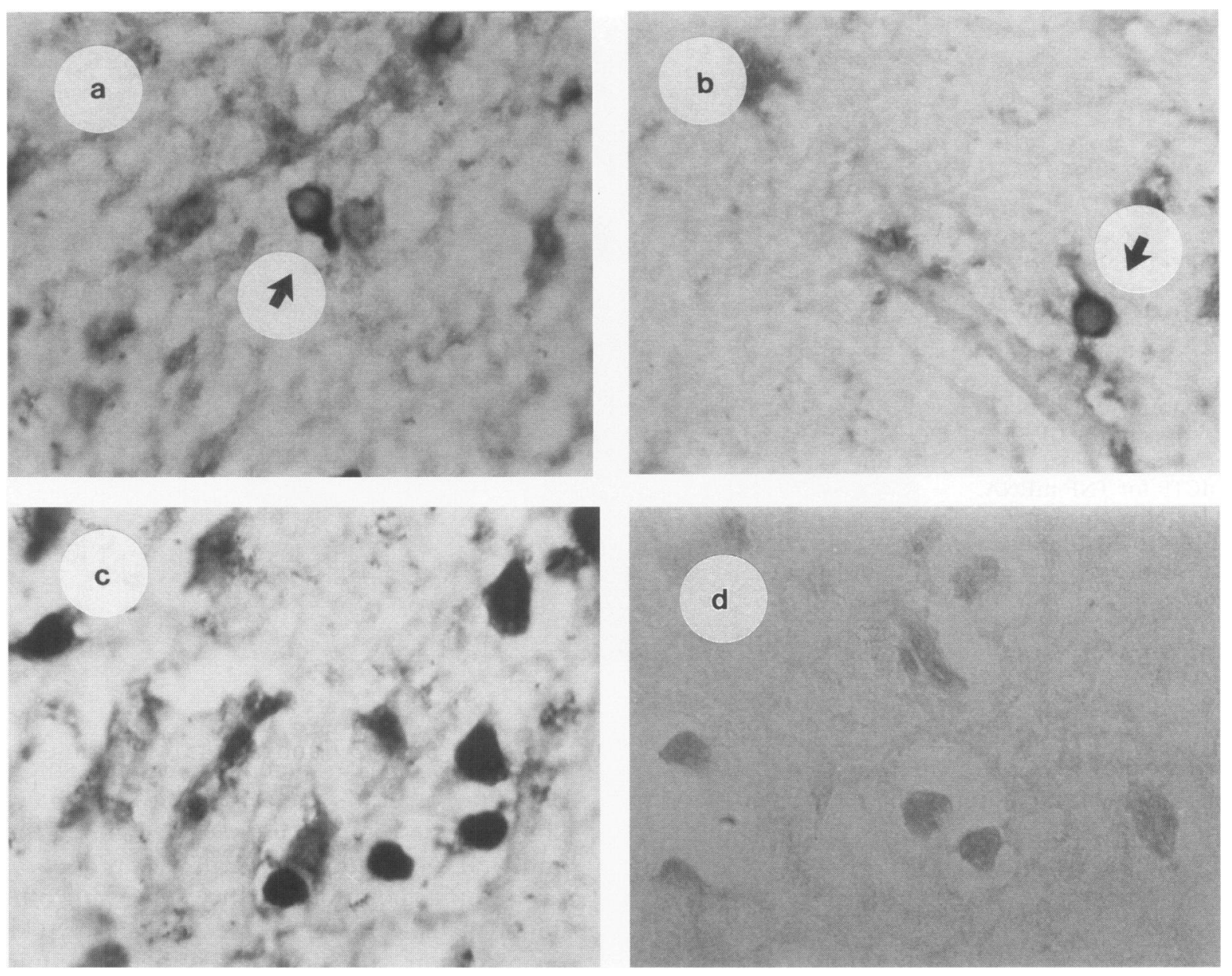

FIG. 3. Detection of cytokine mRNA in the CNS in a patient with AIDS dementia

MIP- $1 \alpha(a)$ and MIP-1 $\beta$ (b) were detected after DNase digestion and RT in situ PCR in cells in the areas where the HIV-1-infected cells were most plentiful in this patient with AIDS dementia. Note the cytoplasmic localization of the signal in scattered cells whose cytoplasmic extensions and large, round nuclei are suggestive of astrocytes. This is to be contrasted with the nuclear-based signal for the control in which the DNase step is omitted (c); no signal is evident after DNase digestion and RT in situ PCR if irrelevant (HPV-specific) primers are used (d).

To determine if viral-infected cells were expressing cytokines, colabeling of viral RNA and cytokine mRNA was performed. These experiments demonstrated that cytokine expression occurred primarily in the HIV-1-negative cells that were in close proximity to viral infected cells (Fig. 4). Specifically, in the areas where there were many HIV-1-positive cells, the number of HIV-1-negative cells that were expressing a cytokine was 5 -fold greater than the number of HIV-1-positive cells.

\section{DISCUSSION}

The primary findings of this study were that expression of TNF, iNOS, MIP- $1 \alpha$, and MIP- $1 \beta$ was strongly correlated to AIDS dementia, occurred in regions where HIV-1-infected cells were most plentiful, and localized primarily to the viralnegative cells. This strongly suggests that the pathogenesis of AIDS dementia is based on cellular damage due to direct infection by HIV-1, amplified by cytokine expression in neighboring uninfected cells.

Cytokine production plays an essential role in the pathophysiology of AIDS by modulating viral activation, inflammatory cell recruitment and function, and tissue damage $(12,13)$. Perhaps the best-characterized cytokine in this regard is TNF. TNF can hinder neuronal function, cause increased viral production in infected glial cells, and cause oligodendroglial cell death (5), which would lead to demyelinization. TNF can enhance the production of other cytokines, in- 
FIG. 4. Colocalization of HIV-1 RNA and cytokine mRNA by combined $R T$ in situ PCR

RT in situ PCR was performed using two different reporter nucleotides (digoxigenin for HIV-1 RNA, blue is signal, and ${ }^{3} \mathrm{H}$ dCTP for TNF MRNA, black grains are signal). The HIV-1 RNA positive cells (small arrow) are adjacent to but distinct from the cells expressing TNF (large arrow).

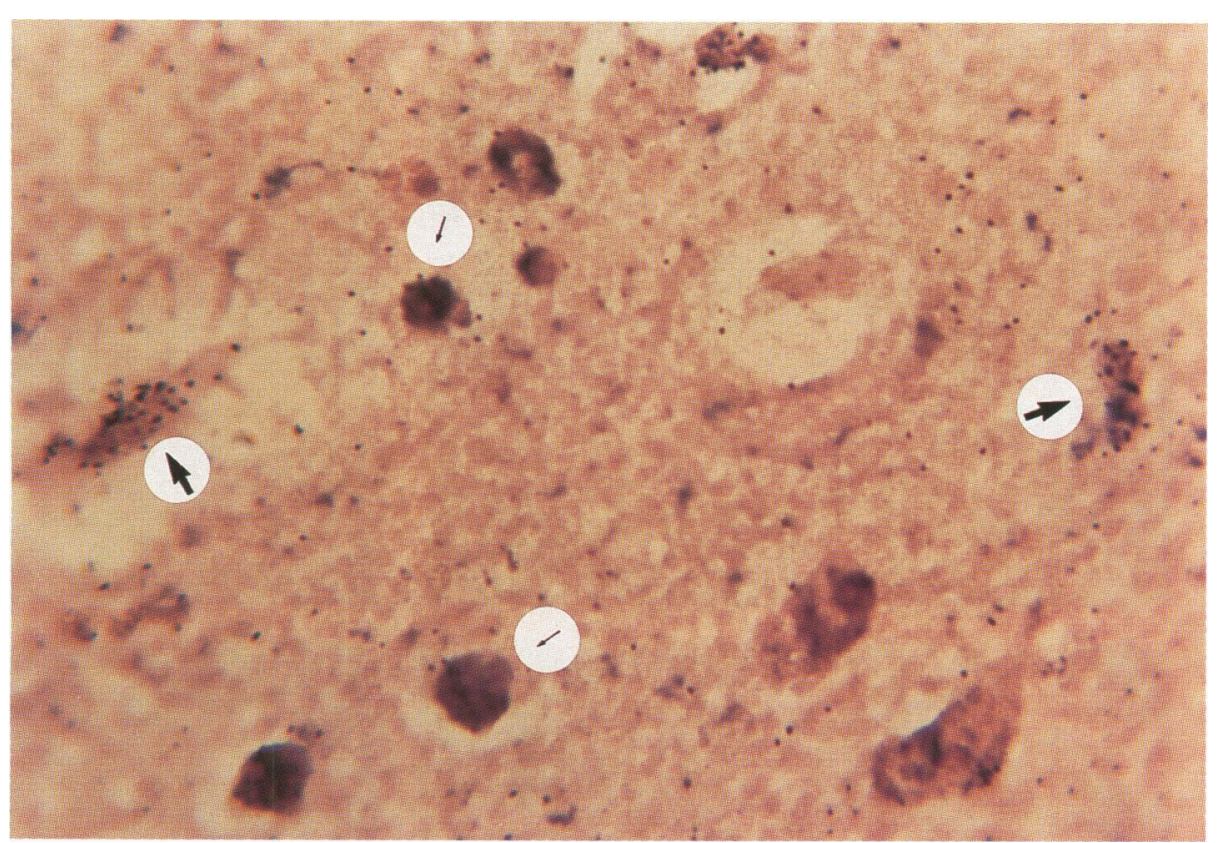

cluding members of the chemoattractant family (chemokines), including MIP-1 $\alpha$ and MIP-1 $\beta$ (13). MIP- $1 \alpha$ selectively attracts $C D 8^{+}$lymphocytes and B cells, whereas MIP- $1 \beta$ recruits $C D 4^{+}$ lymphocytes (19); both are also chemotactic for macrophages. iNOS could contribute to CNS disease by increasing the cytotoxicity of macrophages, by direct cytotoxicity, by disturbance of blood flow, and by possibly enhancing the activity of cytokines such as TNF $(20,21)$. In the cerebral tissues from people with AIDS dementia, cytokine mRNA was readily detectable. A major advantage of the in situ PCR technique is that it allows one to compare easily the geographic distribution of different target sequences. This analysis clearly showed that iNOS, TNF, MIP- $1 \alpha$ and MIP- $1 \beta$ expression, predominately from astrocytes and microglial cells/macrophages, was greatest in the identical areas where the HIV-1infected cells were most plentiful. iNOS, TNF, MIP- $1 \alpha$ and MIP- $1 \beta$ expression was not detectable in the four controls or in the three people with AIDS who did not have CNS symptomatology, providing further evidence for a direct role in AIDS dementia. It should be stressed that the data with iNOS should be considered preliminary, in that iNOS involves a complicated pathway and we did not analyze for downstream correlates of iNOS activity, such as nitrotyrosine. Nonetheless, the findings presented here demonstrate the strong correlation of expression of several cytokines in direct proximity to viral-in- fected cells in AIDS dementia. Further study is needed to ascertain the actual role of each cytokine and the complex interactions among them and viral modulation in the disease process.

Another point of evidence suggesting a predominant role for viral infection and cytokine expression in AIDS dementia is that the number of viral-infected cells and cells expressing a given cytokine in the tissues of the people with AIDS dementia varied with the region of the CNS. Cytokine expression and viral-infected cells were most numerous in the areas of the cerebrum that corresponded to regions of symptomatology and were less common in sections where the neurological examination suggested minimal impairment in these people, specifically, the midbrain and cerebellum.

This study confirmed our previous observation that HIV-1 DNA is readily detectable by PCR in situ hybridization in tissues of the CNS from patients who died of AIDS, even when there was minimal clinical or pathologic evidence of neurological disease. However, in most cases viral DNA was detectable only when the in situ hybridization was preceded by PCR, and in those cases where the provirus was demonstrated by standard in situ hybridization the number of positive cells was dramatically increased after amplification. This indicates that the proviral copy number is usually below the 10-copy detection threshold, which is consistent with other studies that examined HIV-1-infected cell lines and tis- 
sues from a variety of sites $(9,14-16)$. The number and range of cells with the provirus varied considerably in the tissues from patients with AIDS dementia versus those without CNS symptomatology. In patients with AIDS dementia, infected astrocytes and microglia were noted, and up to $18 \%$ of neurons in sections from the cerebrum were viral positive. In patients without CNS symptomatology, far fewer infected cells were seen: less than $1 \%$ of microglial cells in a given section contained the provirus, and infected neurons or astrocytes were not identified. The infection in people without CNS symptomatology appeared to be latent, as the HIV-1 DNA positive cells were negative for viral RNA. One may speculate that this represents early, latent infection with entry of the virus from the peripheral blood to the CNS via monocytes. In comparison, the results from patients with severe CNS symptomatology suggest that the infection by HIV-1 was productive. The ratio of HIV-l DNA/ HIV-1 RNA detection in these tissues was about 1. Furthermore, the equivalent detection of HIV-1 RNA with the primers that correspond to the gag region and the exons from the tat and rev regions is the pattern seen in productive in vitro infection, suggesting the presence of multiply spliced and full-length genomic transcripts $(9,18)$.

In summary, this data suggests a model for AIDS dementia where the initial event is viral entry into the CNS early in the disease process. Perivascular microglial cells may remain latently infected for years. An essential step towards AIDS dementia is activation of viral infection. This is associated with the spread of the virus to many cells in the CNS, including neurons and astrocytes. Although direct damage to astrocytes and neurons would certainly explain part of the disease process, the cellular response, including expression of TNF, iNOS, MIP- $1 \alpha$ and MIP- $1 \beta$, clearly could enhance local tissue damage, increase viral transcription, and ultimately lead to the devastating symptoms characteristic of AIDS dementia.

\section{ACKNOWLEDGMENTS}

This work was supported by grants from the Lewis Foundation, the Perkin-Elmer Corporation, and the Center for Biotechnology of the State of New York (GJN).

I greatly appreciate the technical assistance of Ms. Angella Forde. I thank Dr. Micheal
Bukrinsky for a critical review of the manuscript. I especially appreciate the strong interest of Mr. Salim B. Lewis in the in situ PCR technology and HIV-1 infection.

\section{REFERENCES}

1. Price RW, Brew B, Sidti J, Rosenblum M, Scheck AC, Cleary P. (1988) The brain in AIDS: Central nervous system HIV-1 infection and AIDS dementia complex. Science 239:586-592.

2. Grant I, Atkinson JH, Hesselink JR. (1987) Evidence for early central nervous system involvement in acquired immunodeficiency syndrome and other human immunodeficiency virus infections. Ann. Intern. Med. 107: 828-836.

3. Weiser B, LaNeve D, Eilbott DJ, Seidman R, Burger H. (1990) Human immunodeficiency virus type 1 expression in the central nervous system correlates directly with extent of disease. Proc. Natl. Acad. Sci. U.S.A. 87: 3997-4001.

4. Wiley CA, Schrier RD, Nelson JA, Lampert PW, Oldstone MBA. (1986) Cellular localization of human immunodeficiency virus infection within the brains of acquired immune deficiency syndrome patients. Proc. Natl. Acad. Sci. U.S.A. 83:7089-7093.

5. Tornatore C, Nath A, Amemiya K, Major EO. (1990) Persistent human immunodeficiency virus type 1 infection in human fetal glial cells reactivated by $\mathrm{T}$-cell factor(s) or by the cytokines tumore necrosis factor alpha and interleukin-1 beta. J. Virol. 65:6094-6100.

6. Watkins B, Dorn H, Kelley H, et al. (1990) Specific tropism of HIV-1 for microglial cells in primary human brain cultures. Science 249:549-553.

7. Cvetkovich TA, Lazar E, Blumberg BM, et al. (1992) Human immunodeficiency virus type 1 infection of neural xenografts. Proc. Natl. Acad. Sci. U.S.A. 89:5162-5166.

8. Harouse JM, Bhat S, Spitalnik SL, et al. (1991) Inhibition of entry of HIV-1 in neural cell lines by antibodies against galactosyl ceramide. Science 253:320-322.

9. Nuovo GJ, Gallery F, MacConnell P, Braun A. (1994) In situ detection of PCR-amplified HIV-1 nucleic acids and tumor necrosis factor RNA in the central nervous system. Am. J. Pathol. 144:659-666. 
10. Lipton SA. (1991) HIV-1 related neurotoxicity. Brain Pathol. 1:193-199.

11. Yamada M, Zurbriggen A, Oldstone M, Fujinami R. (1991) Common immunologic determinant between human immunodeficiency virus type $1 \mathrm{gp} 4 \mathrm{l}$ and astrocytes. $J$. Virol. 65:1370-1376.

12. Dubrovsky L, Ulrich P, Nuovo GJ, Manogue KR, Cerami A, Burkinsky M. (1995) Nuclear localization signal of HIV-1 as a novel target for therapeutic intervention. Mol. Med. 1:217-230.

13. Schmidtmayerova $H$, Notte HS, Nuovo GJ, et al. (in press) HIV-1 infection alters chemokine $\beta$ peptide expression in human monocytes: Implications for recruitment of leukocytes into brain and lymph nodes. Proc. Natl. Acad. Sci. U.S.A. (In press).

14. Nuovo GJ. (1994) PCR in Situ Hybridization: Protocols and Applications. 2nd Ed., Raven Press, New York.

15. Nuovo GJ, Becker J, Margiotta $M$, Burke $M$, Fuhrer J, Steigbigel R. (1994) In situ detection of PCR-amplified HIV-1 nucleic acids in lymph nodes and peripheral blood in asymptomatic infection and advanced stage AIDS. J. Acquir. Immune Defic. 7:916-923.

Contributed by A. Cerami on February 23, 1996.
16. Bagasra O, Hauptman SP, Lischer HW, Sachs M, Pomerantz RJ. (1992) Detection of human immunodeficiency virus type 1 provirus in mononuclear cells by in situ polymerase chain reaction. $N$. Engl. J. Med. 326:13851391.

17. Nuovo GJ, Forde A. (1995) An improved system for reverse transcriptase in situ PCR. J. Histotech. 18:295-299.

18. Seshamma P, Bagasra O, Oakes J, Pomerantz RJ. (1992) Quantitative RT PCR for HIV-1 RNA specific species. J. Virol. Methods 40:331-346.

19. Dawson VL, Dawson TM, London ED, Bredt DS, Snyder SH. (1991) Nitic oxide mediates glutamate neurotoxicity in primary cortical cultures. Proc. Natl. Acad. Sci. U.S.A. 88:63686371.

20. Buttery LDK, Evans TJ, Cohen J, Polak JM. (1994) Immunohistochemical localization of inducible nitric oxide synthetase in endotoxin treated rats. Lab. Invest. 71:755-764.

21. Huang Z, Huang PL, Dalkara T, Fishman MC, Moskowitz MA. (1994) Effect of cerebral ischemia in mice deficient in neuronla nitic oxide synthetase. Science 265:1883-1885. 